\title{
VTCN1 Positive
}

National Cancer Institute

\section{Source}

National Cancer Institute. VTCN1 Positive. NCI Thesaurus. Code C160882.

An indication that VTCN1 expression has been detected in a sample. 